\title{
Contraception use and unplanned pregnancies among injection drug-using women in St Petersburg, Russia
}

\author{
Nadia Abdala, ${ }^{1}$ Trace Kershaw, ${ }^{1}$ Tatiana V Krasnoselskikh, ${ }^{2}$ Andrei P Kozlov ${ }^{2}$
}

\author{
'Yale School of Public Health, \\ New Haven, CT, USA \\ ${ }^{2}$ The Biomedical Center, \\ St Petersburg, Russia

\section{Correspondence to} \\ Dr Nadia Abdala, Yale School of \\ Public Health, 60 College Street, \\ New Haven, CT 06520-8034, \\ USA; \\ nadia.abdala@yale.edu
}

Received 30 September 2010 Accepted 5 January 2011 Published Online First 14 April 2011

\begin{abstract}
Background This cross-sectional study estimated the prevalence of contraceptive methods and investigated whether abortion rates influence contraceptive behaviour among injection drugusing (IDU) women in St Petersburg, Russia.

Methodology A self-administered questionnaire of behaviour in the last 3 months was applied to a convenient sample of IDU women. Results Of 80 sexually active participants, $67 \%$ had had an abortion. No participant reported using hormonal contraceptives or intrauterine devices (IUDs). The only valid method of contraception used was condoms, which was reported by half of the participants. Consistent condom use was reported by $22 \%$ of participants and was no more likely among those who had an abortion. Condom use was significantly associated with having multiple or casual sex partners [prevalence ratio (PR) 1.75, 95\% (confidence interval) CI 1.11-2.78, $p=$ $0.01]$, having an IDU sex partner (PR 0.55, 95\% $\mathrm{Cl} 0.36-0.85, p=0.029$ ) and with a negative attitude toward condoms (PR $0.53,95 \% \mathrm{Cl}$ $0.33-0.84, p=0.01)$. Abortions were less likely among those who had multiple or casual sex partners (PR 0.69, 95\% Cl 0.49-0.97, $p=0.03$ ). Conclusions Despite the high prevalence of abortions among IDU women, none reported the use of hormonal contraception or IUDs. Having had an abortion was not associated with greater likelihood of using condoms. Participants mostly used condoms with casual or multiple sex partners, suggesting that condoms were used mainly to prevent HIV/ sexually transmitted infection transmission and not to prevent pregnancy. Programmes to prevent unwanted pregnancies and reduce abortion-related health risks among this understudied vulnerable group are needed.
\end{abstract}

\section{Introduction}

To date, the HIV epidemic in Russia has been mainly driven by injecting drug users, ${ }^{1-3}$ and women are estimated

\section{Key message points}

The prevalence of abortions among injection drug-using women in St Petersburg, Russia is high and none of the participants reported using hormonal contraceptives.

> Having had an abortion was not associated with greater likelihood of using condoms.

> Condoms were used mainly to prevent HIV/sexually transmitted infection transmission and not to prevent pregnancy, indicating a need for programmes to prevent unwanted pregnancies and abortion-related health risks among this vulnerable and understudied group.

to make up $20-40 \%$ of the drug-using population. ${ }^{3-5}$ Concerns about a generalised HIV epidemic ${ }^{6}$ have led to an increased focus on efforts to reduce HIV sexual risks among drug injectors, whereas other important health risks have received less attention in this high-risk group. Unwanted pregnancy, for example, particularly among individuals who inject illicit drugs, may have marked consequences. Unwanted pregnancies can result in abortion, spontaneous abortion, or carrying the baby to term. Pregnancy among active illicit drug injectors can lead to negative health consequences for the mother and baby such as low birthweight, delivery complications and infants with neurobehavioral disorders. ${ }^{8}$

Abortion has been the primary means of preventing births in the Soviet Union ${ }^{9} 10$ and the abortion rates in Russia remain among the highest in the world today. ${ }^{11}$ Although abortion is legal in Russia, and legal pregnancy termination poses little risk to maternal health compared to illegal or unsafe procedures, ${ }^{9} 1213$ outdated techniques may make even legal abortions threatening to women's health due to a greater prevalence of complications. ${ }^{14}$ Complications may occur within 6 months following the procedure, making the quality of abortion procedures largely dependent on postabortion services and resources 
available to the facility providing follow-up health care. $^{914} 15$ Abortion procedures, when performed unsafely, in addition to posing a stress to an already overburdened health care system ${ }^{10} 14$ may lead to substantial health problems including sterility, infections or sepsis, severe bleeding and even death. ${ }^{116}$ Although the number of complications from abortions is substantially lower in Russia compared to countries with strict legal restrictions against abortions, ${ }^{11}{ }^{17}$ data from the Russian Ministry of Health indicate that women still obtain illegal abortions and most abortion-related maternal mortality is due to illegal abortions. ${ }^{911} 16$

The risks associated with abortion are higher among injection drug-using (IDU) women because they are already more likely to have poorer health conditions and comorbid conditions such as hepatitis $\mathrm{C}$ virus, HIV and other addictive disorders. ${ }^{18} 19$ Female IDUs may be more vulnerable to impoverishment and discrimination, ${ }^{20-22}$ making it more difficult for them to receive appropriate health care. Especially in Russia, where there is a lack of integrated medical services and medical treatment is strictly separated by discipline, individuals with multiple health conditions are more likely to have unattended health needs. ${ }^{22-24}$

Because many health care providers regard drug dependence as an issue of morality rather than a medical disorder, ${ }^{24}$ injectors may be reluctant to seek treatment for acute issues (e.g. opiate overdoses or abscesses). ${ }^{24} 25$ The range of available treatment programmes for opioid users in Russia is limited and available services are inaccessible to many. With opioid maintenance treatment being illegal, ${ }^{24}{ }^{26}$ abstinence is the only prevalent approach in state programmes and the provision of detoxification outside of the state-run narcological services is illegal. ${ }^{21} 27$

Fear of disclosure of medical registration data is another factor that may drive potential patients underground or into non-official care. ${ }^{25}{ }^{26}$ Yet in Russia, access to free specialised medical care is contingent upon residency registration and registration data containing information on illicit drug use that may be shared by practice or by law with social service providers and law enforcement authorities. ${ }^{21} 2428$ This may lead to harassment by police or loss of basic privileges such as driving licenses, employment and parental rights. ${ }^{24} 2930$ Although anonymous services are available, which implies that patients must not provide their names when seeking treatment, ${ }^{26}$ these services require a fee. Because the Russian health care system often relies on informal fees ${ }^{23}{ }^{26}$ for certain laboratory tests, medications or physician services, ${ }^{24} 26$ many health services are unavailable or of substandard quality for patients unable to provide out-of-pocket payments. ${ }^{26}{ }^{31}$ Moreover, harm reduction interventions that can reduce the adverse health, social and economic effects of substance use problems without requiring abstinence remain extremely limited in Russia, ${ }^{25-27}$ further depriving substance users of alternate forms of social support, information, counselling and medical care. ${ }^{25}$ Thus, the data suggest that the more vulnerable IDU women might face greater barriers to access to birth control and appropriate reproductive care..$^{32} 33$ Although efforts to prevent unwanted pregnancies in Russia have been implemented and were widely effective, ${ }^{34-37}$ to our knowledge there has been no public health effort to improve the reproductive health of vulnerable female injectors.

Because to date no study has looked at the prevalence of pregnancy prevention methods among IDU women in Russia, we conducted an initial study of contraceptive use and unplanned pregnancies among IDU women in St Petersburg. The aim of this study was to describe the prevalence of contraceptive use (including condoms), and of abortion, and to assess whether a history of abortion influences current contraceptive behaviour. We hope this study will provide direction for methods to improve reproductive health among IDU women in Russia.

\section{Methods}

\section{Study population and recruitment of subjects}

A convenience sample of IDU women who presented to receive free medical care at the Biomedical Center in St Petersburg, Russia between December 2003 and December 2004 were consecutively offered the opportunity to participate in this study. Participants were told that their participation or refusal to participate in this study would affect neither their receipt of health services nor their ability to participate in other studies. Individuals who agreed to participate received a gift, with a value equivalent to US $\$ 5$, consisting of condoms, food items (e.g. tea, coffee and milk) or T-shirts. Participants were asked to respond to a confidential self-administered questionnaire before receiving a free examination by the dermatovenereologist and being tested for sexually transmitted infections (STIs) at the clinic. The study protocol was approved by the Human Investigation Committees of Yale University in the USA and the Biomedical Center in St Petersburg, Russia and required written informed consent from participants.

The Biomedical Center began offering free medical care to IDU men and women in 2002 with the recruitment of active illicit drug injectors for participation in a cohort study. Drug injectors who presented at the Center in response to recruitment, whether or not they enrolled in the cohort study, and those who learned of the Center through their friends and field workers, were entitled to receive free medical care at the Center. Any IDU woman receiving free medical care at the Biomedical Center was allowed to participate in the current study. This was an independent study and the information presented herein was not part of a larger study, nor has it been published elsewhere.

In total, 85 unique women who reported injecting illicit drugs in the past 3 months were accepted into this study. Information on those who declined to 
participate in the study was not collected. However, administrative records indicate that the total number of injectors who were tested for STIs in the laboratory at the Biomedical Center between December 2003 and December 2004 was 251, and the ratio of male:female patients was approximately $2: 1$, indicating that the total number of women who were tested was around $84(251 \times 1 / 3)$. Therefore, we estimate that almost all IDU women who received services at the Center were recruited into the present study.

\section{Measures}

The self-administered questionnaire used in this study was a modified version of a questionnaire used in a prior study ${ }^{38}$ that was adapted from questionnaires administered to needle exchange programme users in St Petersburg, Russia. ${ }^{39} 40$ Modifications were constructed in English, translated into Russian and translated back into English to ensure linguistic consistency. The questionnaire required approximately 40 minutes to complete.

Information was collected on the demographic characteristics of subjects including age, gender, education, employment and marital status. Participants were asked about the frequency of their injection drug use and about their sexual behaviour in the 3 months prior to the interview, including frequency of sexual intercourse, number of sexual partners and how often they

\begin{tabular}{|c|c|c|}
\hline Characteristic & $n$ & $\%$ * \\
\hline \multicolumn{3}{|l|}{ Demographics } \\
\hline Age [median years: minimum 18 and maximum 42 (IQR)] & 26 & $(22-30)$ \\
\hline Uncompleted secondary school & $9 / 80$ & 11 \\
\hline Employed & $24 / 80$ & 30 \\
\hline Officially married & $16 / 79$ & 20 \\
\hline \multicolumn{3}{|l|}{ Substance use } \\
\hline \multicolumn{3}{|l|}{ Frequency of drug injection } \\
\hline Injected less than once a week & $31 / 75$ & 41 \\
\hline Injected weekly or more often & $44 / 75$ & 59 \\
\hline \multicolumn{3}{|l|}{ Sexual behaviour of subjects in the last 3 months } \\
\hline \multicolumn{3}{|l|}{ Sex frequency } \\
\hline Sex up to three times a month & $16 / 68$ & 24 \\
\hline Sex once a week or more & $52 / 68$ & 76 \\
\hline \multicolumn{3}{|l|}{ Sex partner type and number } \\
\hline Had one 'regular' sexual partner only & $41 / 80$ & 51 \\
\hline Had a 'casual' sex partner or $>1$ partner & $39 / 80$ & 49 \\
\hline \multicolumn{3}{|l|}{ Partner's IDU status } \\
\hline Partner is IDU & $46 / 77$ & 60 \\
\hline Partner is not IDU & 19/77 & 25 \\
\hline Some are IDU some are not & $5 / 77$ & 6 \\
\hline Don't know & $7 / 77$ & 9 \\
\hline \multicolumn{3}{|l|}{ Women's health issues } \\
\hline \multicolumn{3}{|l|}{ Use of contraceptive procedures } \\
\hline None & $25 / 78$ & 32 \\
\hline Condoms & $40 / 78$ & 51 \\
\hline Traditional methods (i.e. douching or withdrawal) & $12 / 78$ & 15 \\
\hline Spermicides (i.e. intravaginal creams, solutions or suppositories) & $1 / 78$ & 1 \\
\hline Hormonal contraceptives or intrauterine device use & $0 / 78$ & 0 \\
\hline Always use condoms & $17 / 76$ & 22 \\
\hline \multicolumn{3}{|l|}{ History of pregnancies } \\
\hline Currently pregnant & $6 / 78$ & 8 \\
\hline Had been pregnant & $62 / 78$ & 80 \\
\hline Had miscarried & $12 / 78$ & 15 \\
\hline Had an abortion & $52 / 78$ & 67 \\
\hline Had delivered to full term & $33 / 78$ & 42 \\
\hline Negative attitude about condom use ${ }^{\dagger}$ [median: minimum 12 and maximum 27 (IQR)] & 19.5 & $(16-21)$ \\
\hline
\end{tabular}


used condoms. Participants were asked if the sexual partners were casual or regular partners and if any of their sexual partners injected drugs.

Participants were asked which contraceptive methods they used from a list that included: none; condoms; washing of the genitals; vaginal douching; intravaginal creams, suppositories and/or solutions; hormonal contraceptives; intrauterine devices (IUDs); interrupted sexual intercourse; and an option to write down the contraceptive method used. These methods were collapsed into five categories: (1) none, (2) condoms, (3) traditional methods (vaginal douching or washing of the genitals, counting days, or withdrawal), (4) spermicides (i.e. intravaginal creams, solutions, suppositories) and (5) hormonal contraceptives, IUDs or other. Those who reported using hormonal contraceptives, IUDs or condoms were classified as having used reliable contraceptive methods. Those who reported using a traditional method or spermicides were classified as having used an unreliable method. Participants were asked if they were pregnant, if they had ever been pregnant, if they had ever had an abortion or a fullterm delivery.

Standard descriptive statistics were applied to the study sample. Bivariate analysis was used to identify associations between the prevalence of contraceptive use, and of abortion, and other characteristics of the participants. Analysis was conducted using SPSS $16^{\mathrm{TM}}$ software (SPSS, IBM Corporation, Somers, NY, USA). Prevalence ratios (PRs) were calculated instead of OR because occurrence of outcomes was common (>10\%). ${ }^{4142}$

\section{Results}

\section{General characteristics of the subjects}

Of the 85 participants recruited for the study, five were not sexually active and were excluded from the analysis. The women's median age was 26 years (Table 1 ), the majority had completed secondary education, one-third of the participants were employed and 20\% were legally married. Of those who answered, more than half reported injecting on a weekly basis or more often, and three-quarters had sex on a weekly basis or more often. Half of the participants reported having had either a casual sex partner or more than one sex partner in the last 3 months. Some $66 \%$ of the subjects reported that at least one of their sex partners in the last 3 months had injected illicit drugs.

\section{Contraceptive use and pregnancy rates}

No participant reported using more than one contraceptive method. Thirty-two percent $(25 / 78)$ of IDU women reported no contraceptive use and 51\% (40/78) reported using condoms. A total of $17 \%$ (13/78) of the women reported using unreliable contraceptive methods; $15 \%(12 / 78)$ used traditional methods, and one woman (1\%) reported using spermicides as the only method of contraception. No participant reported the use of hormonal contraceptives or IUDs within the previous 3 months. Eighty percent (62/78) of participants reported having been pregnant, and 67\% (52/78) reported having had an abortion. In total, $84 \%$ of the women who reported having been pregnant (52/62) also reported having had an abortion. Twenty-two percent (17/76) of the participants reported consistent condom use (i.e. 'always' using condoms).

\section{Condom use and abortion rates}

In bivariate analysis, neither condom use nor consistent condom use (i.e. 'always' using condoms) was significantly associated with having had an abortion. Having had an abortion was more likely to be reported by participants aged over 26 years (the median age) (PR 1.44, $95 \%$ CI $1.02-2.03, p=0.03$ ) and was less likely to be reported by those who had multiple or casual sex partners within the last 3 months (PR 0.69, 95\% CI $0.49-0.97, p=0.03$ ).

The use of condoms as a contraceptive method was more likely to be reported by participants who had multiple or casual sex partners in the previous 3 months (PR 1.75, 95\% CI 1.11-2.78, $p=0.01$ ) and less likely by those who displayed negative attitudes toward condoms (PR 0.53, 95\% CI 0.33-0.84, $p=$ 0.01 ) and those who reported having at least one IDU sex partner within the last 3 months (PR $0.55,95 \%$ CI $0.36-0.85, p=0.029$ ).

Consistent condom use during the last 3 months was more likely to be reported by participants who had multiple or casual sex partners in the last 3 months (PR 2.53, 95\% CI 0.99-6.48, $p=0.05$ ) and less likely among those displaying a negative attitude toward condoms (PR 0.23, 95\% CI 0.08-0.65, $p=0.003$ ). There was no significant association between report of consistent condom use and having had an abortion.

\section{Discussion}

This is the first study to report the prevalence of contraceptive use and unplanned pregnancies among IDU women in St Petersburg, Russia. The aim of this study was to provide a direction for programmes that address the health of IDU women in Russia.

Although all the participants in this study were sexually active and the majority of respondents reported having sex at least weekly, none of the participants reported using hormonal contraceptive methods. The only effective method of contraception used was condoms. These results may reflect a general negative attitude toward hormonal contraception that has been observed in other studies ${ }^{33} 43$ and may confirm findings showing that the barrier method is the most popular or available form of contraception in Russia. ${ }^{14445}$

Half the participants did not use any effective form of contraception, suggesting that IDU women may be at greater risk for unintended pregnancies compared to other groups of women in St Petersburg. On one hand, one-third of participants did not use any form of contraception, which is a somewhat higher prevalence 
than the $12-25 \%$ found in other studies among women in St Petersburg. ${ }^{33} 4546$ Conversely, $15 \%$ of women reported using traditional methods of contraception. These methods are considered unreliable given the high rates of unwanted pregnancies among women who use them as their main form of contraception. ${ }^{14}$ Other studies in Russia showed greater numbers of women (around 20\% and 40\%, respectively) using traditional or unreliable methods. ${ }^{1433} 46$ The results confirm findings indicating that traditional contraceptive methods, which used to be popular in Russia, are still in use by many women ${ }^{91433}$ and that many Russian women consistently choose to not use contraceptives. ${ }^{147}$

Two-thirds of the study participants reported having had an abortion, which confirms the already known fact that abortions are highly prevalent in Russia ${ }^{14} 48$ and that many Russian women rely on abortion as a contraceptive procedure. ${ }^{1433}$ This abortion prevalence is in the range of the prevalence found in Northwestern Russian cities, where between half and three-quarters of non-IDU women had undergone an abortion, ${ }^{48} 49$ but is higher than the $55 \%$ abortion prevalence found among urban women from St Petersburg. ${ }^{50}$

Although the majority of participants displayed a mostly negative attitude toward condoms, studies showing that lower socioeconomic status can be associated with lack of condom use ${ }^{47}$ and a lack of hormonal contraceptive use ${ }^{45}$ suggest that financial constraints may play a role in the high abortion rates and lack of contraceptive use among IDU women. One study conducted among abortion clients in Russia identified a group of women who underwent repeat abortion procedures as being disadvantaged and more likely to report economic reasons for the abortion. ${ }^{14}$ Another study, an operations research project in the city of Perm in Russia, showed that with the exception of IUDs, the financial cost of using a contraceptive method over the course of 1 year was significantly higher than the cost of abortion, when additional costs (e.g. due to complications) were not taken in consideration. ${ }^{15}$ Thus, many Russian women might perceive abortion to be more affordable than consistent contraceptive use.

Neither consistent condom use nor levels of condom use, in general, differed between those with and without a history of abortion, suggesting that the consequence of an unwanted pregnancy, by itself, was insufficient to lead participants to use an effective contraception method. The results are consistent with studies in Russia, showing that history of abortion does not correlate with reliable contraceptive use. ${ }^{14} 45$ Studies in other parts of the world have shown greater likelihood of contraceptive use among women who underwent abortion. ${ }^{47} 5152$ The results could indicate a lack of access to effective contraceptive methods or obstacles to female reproductive health care services. ${ }^{103353}$ Future studies will need to investigate the reasons for abortions and lack of contraceptive use among this population.
Condoms were primarily used by participants who reported having casual or multiple sex partners, indicating that they are primarily used as a measure to prevent transmission of HIV/STIs, ${ }^{54} 55$ not to prevent pregnancy. Contrary to a study that found abortions to be associated with having multiple sex partners, ${ }^{50}$ in the present study individuals who had casual or multiple sex partners were less likely, not more, to report having had an abortion, probably reflecting the higher prevalence of condom use among this group. The results suggest that abortions were not the result of higher HIV sexual risk behaviours, but rather were associated with a lack of contraceptive use.

That IDU women who had at least one IDU sex partner were less likely to use condoms confirms results from studies showing the important role of sex partners in decisions to use contraception. Studies have found that condoms are less likely to be used among people who inject together with their sexual partner, ${ }^{56}$ who are in unstable relationships and have infrequent $\operatorname{sex},{ }^{33}$ or who report partner violence. ${ }^{4757}$ The results emphasise the importance of including the participant's sexual partners in any efforts to prevent unwanted pregnan$\operatorname{cies}^{58}$ and improve the health of IDU women. ${ }^{14}$

The main limitation of this study is the small sample size, which restricted the analyses that could be conducted, and indicates a need for larger-scale studies to confirm these results. We did not ask how many times individuals had an abortion. The fact that participants were recruited by convenience limits the generalisability of the results. However, the study provides a unique opportunity for the identification of health problems among IDU women who are not institutionalised and who might therefore be more difficult to reach.

\section{Conclusions}

The results show that half of all IDU women did not use any effective contraceptive method to prevent pregnancy. The only effective contraceptive method used was condoms and none of the respondents used hormonal contraception. Participants mostly used condoms with casual or multiple sex partners, suggesting that condoms were likely used to prevent HIV/ STI transmission and not as a method of contraception. The high prevalence of abortion and the low levels of consistent condom use indicate a high risk for unwanted pregnancies and abortion-related health risks among this understudied sample of IDU women in St Petersburg, Russia. Programmes are needed to prevent unwanted pregnancies among this vulnerable group.

Acknowledgements The authors want to thank Mr Michael Greenwood who assisted in proofreading the manuscript.

Funding This work was supported by a grant from NIH U01 A147987-05 part of the NIH HIV Prevention Trials Network (HPTN) to the Biomedical 
Center and the University of North Carolina at Chapel Hill and by Fogarty International Center and Yale University AIDS International Training and Research Program (AITRP) (5D43 TW001028).

\section{Competing interests None.}

Ethics approval Ethics approval was granted by the Human Investigation Committees of Yale University in the USA and the Biomedical Center in St Petersburg, Russia.

Provenance and peer review Not commissioned; externally peer reviewed.

\section{References}

1 Lowndes CM, Alary M, Platt L. Injection drug use, commercial sex work, and the HIV/STI epidemic in the Russian Federation. Sex Transm Dis 2003;30:46-48.

2 Platt L, Rhodes T, Lowndes CM, et al. Impact of gender and sex work on sexual and injecting risk behaviors and their association with HIV positivity among injecting drug users in an HIV epidemic in Togliatti City, Russian Federation. Sex Transm Dis 2005;32:605-612.

3 Shaboltas AV, Toussova OV, Hoffman IF, et al. HIV prevalence, sociodemographic, and behavioral correlates and recruitment methods among injection drug users in St. Petersburg, Russia. J Acquir Immune Defic Syndr 2006;41:657-663.

4 Abdala N, White E, Toussova OV, et al. Comparing sexual risks and patterns of alcohol and drug use between injection drug users (IDUs) and non-IDUs who report sexual partnerships with IDUs in St. Petersburg, Russia. BMC Public Health 2010;10:676.

5 Gyarmathy VA, Li N, Tobin KE, et al. Unprotected sex in heterosexual partnerships of injecting drug users in St. Petersburg, Russia. AIDS Behav 2011;15:58-64.

6 Beyrer C, Baral S, Shaboltas A, et al. The feasibility of HIV vaccine efficacy trials among Russian injection drug users. Vaccine 2007;25:7014-7016.

7 Iguchi MY, Ober AJ, Berry SH, et al. Simultaneous recruitment of drug users and men who have sex with men in the United States and Russia using respondent-driven sampling: sampling methods and implications. J Urban Health 2009;86(Suppl. 1):5-31.

8 Zuckerman B. Developmental consequences of maternal drug use during pregnancy. NIDA Res Monogr 1985;59:96-106.

9 CDC and ORC Macro. Reproductive, Maternal and Child Health in Eastern Europe and Eurasia: A Comparative Report. Atlanta, GA: Population Reference Bureau, 2003.

10 Popov AA. Family planning in the USSR. Sky-high abortion rates reflect dire lack of choice. Entre Nous Cph Den 1990;16:5-7.

11 Ipas. Russia: Reproductive Health and Abortion Statistics. International Data for Evaluation of Abortion Services. Chapel Hill, NC: Ipas, 2007.

12 Berer M. Making abortions safe: a matter of good public health policy and practice. Bull World Health Organ 2000;78:580-592.

13 Zhirova IA, Frolova OG, Astakhova TM, et al. Abortion-related maternal mortality in the Russian Federation. Stud Fam Plann 2004;35:178-188.

14 David PH, Reichenbach L, Savelieva I, et al. Women's reproductive health needs in Russia: what can we learn from an intervention to improve post-abortion care? Health Policy Plan 2007;22:83-94.
15 Savelieva I, Pile JM, Sacci I, et al. Postabortion Family Planning Operations Research Study in Perm, Russia. Atlanta, GA: Frontiers in Reproductive Health, 2003.

16 Gurina NA, Vangen S, Forsén L, et al. Maternal mortality in St. Petersburg, Russian Federation. Bull World Health Organ 2006;84:283-289.

17 Henshaw SK, Singh S, Haas T. The incidence of abortion worldwide. Int Fam Plann Persp 1999;25:S30-S38.

18 Krupitsky EM, Zvartau EE, Lioznov DA, et al. Co-morbidity of infectious and addictive diseases in St. Petersburg and the Leningrad Region, Russia. Eur Addict Res 2006;12:12-19.

19 Paintsil E, Verevochkin SV, Dukhovlinova E, et al. Hepatitis C virus infection among drug injectors in St Petersburg, Russia: social and molecular epidemiology of an endemic infection. Addiction 2009;104:1881-1890.

20 Fiellin DA, Green CT, Heimer R. Combating the Twin Epidemics of HIV/AIDS and Drug Addiction. Washington, DC: Centre for Strategic \& International Studies (CSIS) Press, 2008.

21 The Civil Society Organization from the Russian Federation. Discrimination Against Women from Vulnerable Groups, Including Women Who Use Drugs and/or Engage in Sex Work in the Russian Federation. Proceedings of the 46th Session of the Commission on the Elimination of Discrimination Against Women (CEDAW), 12-30 July 2010, New York, NY, USA.

22 Wall M, Schmidt E, Sarang A, et al. Sex, drugs and economic behaviour in Russia: a study of socio-economic characteristics of high risk populations. Int J Drug Policy; 3 November 2010. doi:10.1016/j.drugpo.2010.10.001.

23 Larivaara M, Dubikaytis T, Kuznetsova O, et al. Between a rock and a hard place: the question of money at St. Petersburg women's clinics. Int J Health Serv 2008;38:357-377.

24 Wolfe D, Carrieri MP, Shepard D. Treatment and care for injecting drug users with HIV infection: a review of barriers and ways forward. Lancet 2010;376:355-366.

25 Tkatchenko-Schmidt E, Renton A, Gevorgyan R, et al. Prevention of HIV/AIDS among injecting drug users in Russia: opportunities and barriers to scaling-up of harm reduction programmes. Health Policy 2008;85:162-171.

26 Bobrova N, Rughnikov U, Neifeld E, et al. Challenges in providing drug user treatment services in Russia: providers' views. Subst Use Misuse 2008;43:1770-1784.

27 Elovich R, Drucker E. On drug treatment and social control: Russian narcology's great leap backwards. Harm Reduct J 2008;5:23.

28 Bobrova N, Rhodes T, Power R, et al. Barriers to accessing drug treatment in Russia: a qualitative study among injecting drug users in two cities. Drug Alcohol Depend 2006;82(Suppl. 1):S57-S63.

29 Rechel B. HIV/AIDS in the countries of the former Soviet Union: societal and attitudinal challenges. Cent Eur J Public Health 2010;18:110-115.

30 Sarang A, Rhodes T, Sheon N, et al. Policing drug users in Russia: risk, fear, and structural violence. Subst Use Misuse 2010;45:813-864.

31 Rechel B, McKee M. Health reform in central and eastern Europe and the former Soviet Union. Lancet 2009;374:1186-1195.

32 Dubikaytis $\mathrm{T}$, Larivaara $\mathrm{M}$, Kuznetsova $\mathrm{O}$, et al. Inequalities in health and health service utilisation among reproductive age women in St. Petersburg, Russia: a cross-sectional study. BMC Health Serv Res 2010;10:307.

33 Perlman F, McKee M. Trends in family planning in Russia, 1994-2003. Perspect Sex Reprod Health 2009;41:40-50. 
34 Grimes DA, Gallo MF. Counseling to prevent unintended pregnancies: measuring its value. Womens Health Issues 2001;11:397-400.

35 Karelova GN. A reduction of abortions. Russian Federation. The Hague Forum. Integration 1999 Summer;60:29.

36 Sherwood-Fabre L, Goldberg H, Bodrova V. The impact of an integrated family planning program in Russia. Eval Rev 2002;26:190-212.

37 Vikhlyaeva E, Nikolaeva E, Brandrup-Lukanow A. Contraceptive use and family planning after labor in the European part of the Russian Federation: 2-year monitoring. Eur J Contracept Reprod Health Care 2001;6:219-226.

38 Abdala N, Krasnoselskikh TV, Durante AJ, et al. Sexually transmitted infections, sexual risk behaviors and the risk of heterosexual spread of HIV among and beyond IDUs in St. Petersburg, Russia. Eur Addict Res 2008;14:19-25.

39 Abdala N, Carney JM, Durante AJ, et al. Estimating the prevalence of syringe-borne and sexually transmitted diseases among injection drug users in St Petersburg, Russia. Int J STD AIDS 2003;14:697-703.

40 Somlai AM, Kelly JA, Benotsch E, et al. Characteristics and predictors of HIV risk behaviors among injection-drug-using men and women in St. Petersburg, Russia. AIDS Educ Prev 2002;14:295-305.

41 Lee J. Odds ratio or relative risk for cross-sectional data? Int J Epidemiol 1994;23:201-203.

42 McNutt LA, Wu C, Xue X, et al. Estimating the relative risk in cohort studies and clinical trials of common outcomes. Am J Epidemiol 2003;157:940-943.

43 Nettleman MD, Brewer J, Ayoola A. Why women risk unintended pregnancy. J Fam Pract 2009;58:E1-E5.

44 Dorman S. More access to contraception? Russian city surveyed. Popul Today 1993;21:5,10.

45 Regushevskaya E, Dubikaytis T, Nikula M, et al. Contraceptive use and abortion among women of reproductive age in St. Petersburg, Russia. Perspect Sex Reprod Health 2009;41:51-58.

46 Regushevskaya E, Dubikaytis T, Nikula M, et al. The socioeconomic characteristics of risky sexual behaviour among reproductive-age women in St Petersburg. Scand J Public Health 2008;36:143-152.
47 Rowlands S. More than one abortion. J Fam Plann Reprod Health Care 2007;33:155-158.

48 Vaktskjold A, Arild V, Paulsen EE, et al. The prevalence of selected pregnancy outcome risk factors in the life-style and medical history of the delivering population in north-western Russia. Int J Circumpolar Health 2004;63:39-60.

49 Talykova LV, Vaktskjold A, Serebrjoakova NG, et al. Pregnancy health and outcome in two cities in the Kola Peninsula, Northwestern Russia. Int J Circumpolar Health 2007;66:168-181.

50 Regushevskaya E, Dubikaytis T, Laanpere M, et al. Risk factors for induced abortions in St Petersburg, Estonia and Finland. Results from surveys among women of reproductive age. Eur J Contracept Reprod Health Care 2009;14:176-186.

51 Bianchi-Demicheli F, Perrin E, Bianchi PG, et al. Contraceptive practice before and after termination of pregnancy: a prospective study. Contraception 2003;67:107-113.

52 Fisher WA, Singh SS, Shuper PA, et al. Characteristics of women undergoing repeat induced abortion. CMAJ 2005;172:637-641.

53 Chalmers B, Sand M, Muggah H, et al. Contraceptive knowledge, attitudes and use among women attending health clinics in St. Petersburg, Russian Federation. Can J Hum Sex 1998;7:129-137.

54 Kumar MS, Virk HK, Chaudhuri A, et al. A rapid situation and response assessment of the female regular sex partners of male drug users in South Asia: factors associated with condom use during the last sexual intercourse. Int J Drug Policy 2008;19:148-158.

55 Vidal-Trecan G, Warszawski J, Coste J, et al. Contraceptive practices of non-HIV-seropositive injecting drug users. Eur J Epidemiol 2003;18:863-869.

56 Marshall BD, Wood E, Zhang R, et al. Condom use among injection drug users accessing a supervised injecting facility. Sex Transm Infect 2009;85:121-126.

57 Kazi S, Reeves MF, Creinin MD. The prevalence of domestic violence in volunteers for abortion and contraceptive research studies. Contraception 2008;78:79-83.

58 Vanichseni S, Des Jarlais DC, Choopanya K, et al. Condom use with primary partners among injecting drug users in Bangkok, Thailand and New York City, United States. AIDS 1993;7:887-891. 